LETTER TO THE EDITOR

\title{
Fluorescent RT in situ PCR detection of MRP1 mRNA in human HCV infect- ed liver
}

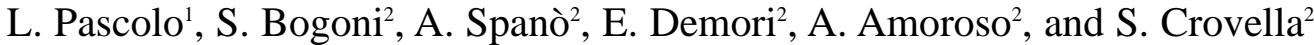

'CSF- Dipartimento BBCM, Università di Trieste. Via Giorgeri 1. 34127 Trieste (Italy) and ${ }^{2}$ Dipartimento Scienze della Riproduzione e dello Sviluppo, Università di Trieste, Servizio di Genetica. IRCCS Burlo Garofolo. Via dell'Istria 65/1. 34137 Trieste (Italy)

Key words:

Chronic hepatitis $\mathrm{C}$ is now a major cause of chronic liver disease, cirrhosis and hepatocellular carcinoma. Approximately $20 \%$ of cases of acute viral hepatitis are due to hepatitis C. Cirrhosis develops in more than $25 \%$ of patients with chronic infection and each year hepatocellular carcinoma occurs in 1-3\% of patients with cirrhosis due to HCV (Hoofnagle 1999).

Patients with hepatocellular carcinoma are characterized by nonresponsiveness to chemotherapeutic agents. A cause of refractivity to treatment has been ascribed to the overexpression of the Pgp (MDR) protein (Kim et al. 1999), and the additional involvement of multidrug resistance-associated proteins (MRPs) has been also hypothesized (Minemura et al. 1999).

Recently, a possible relationship between HBV and the drug sensitivity phenotype of cancer cells has been hypothesized, suggesting that a transcription transactivator encoded by hepatitis B virus $\mathrm{X}$ gene can transactivate the MDRl gene (Dunn et al. 1996). Until now, no data have been reported on a possible correlation between $\mathrm{HCV}$ infection and multidrug resistant phenotype during chronic infection or in hepatocarcinoma due to hepatitis C.

The multidrug resistance-related protein MRP1, together with MDR1, is the major mechanism of resistance to chemotherapeutic agents in different tumors (Hipfner et al. 1999). Since its presence is very low in normal liver, but an overexpression has been reported in hepatocarcinomas as well as during liver regeneration (Matsunaga et al. 1998), we considered the hypothesis of a MRPI varied activation during $\mathrm{HCV}$ infection. Interest in this issue is also justified by the recent in vitro studies of Takeuci et al. (1999) which indicate that MRP1 expression in hepatocytes is reduced by interferon alfa, the only efficient agent in the therapy of chronic hepatitis $\mathrm{C}$.

Different technical approaches have been used for the evaluation of MRPI expression, from immunohistochemistry and in situ hybridization to Northern blot analyses and RT-PCR (Legrand $e t$ al. 1996).

In this study we applied a rapid, sensitive and robust MRPI expression detection protocol based on direct RT-IS-PCR technology and fluorochrome-modified $\left(\mathrm{dCTP}^{\mathrm{Cy} 3}\right)$ nucleotides in order to test the presence of $M R P 1$ mRNA in liver biopsies of individuals with severe HCV infection.

Paraffin-embedded liver biopsies from ten patients with severe $\mathrm{HCV}$ infection (coming from the Istituto di Anatomia Patologica, University of Napoli), previously fixed with $10 \%$ buffered formalin for 16 hours, were dewaxed by xylene treatment ( 1 hour at room temperature) and rehydrated 
to nuclease-free water through graded fresh acqueous solutions of ethanol $(100 \%, 95 \%, 70 \%)$. Slides were rinsed in PBS for $2 \mathrm{~min}$, immersed in a $0.01 \%$ Triton-X 100/PBS solution for $2 \mathrm{~min}$, rinsed in PBS for $2 \mathrm{~min}$. The permeabilization of liver biopsies was performed using $2 \mu \mathrm{g} / \mathrm{ml}$ of proteinase $\mathrm{K}$ (Boehringer Mannheim) at $37^{\circ} \mathrm{C}$ for $30 \mathrm{~min}$.

After proteinase $\mathrm{K}$ inactivation by heat $\left(95^{\circ} \mathrm{C}\right.$ for $1 \mathrm{~min})$ the biopsies were treated with RNA free DNAase (Celbio, Milan) (50 U) at $37^{\circ} \mathrm{C}$ overnight. Reverse transcription (RT) mix, containing random hexamers, were placed on HCV-infected liver biopsies and the reaction mix was covered with silicon AmpliCover Discs (PE Biosystems) and assembly completed with overlay of the AmpliCover Clips (PE Biosystems). RT reaction was performed with MMULV reverse transcriptase (PE Biosystems) for $30 \mathrm{~min}$ at $42^{\circ} \mathrm{C}$ in the GeneAmp in situ PCR System 1000 (PE Biosystems).

Slides were then disassembled and the biopsies post-fixed by heat treatment $\left(60^{\circ} \mathrm{C}\right.$ for $\left.5 \mathrm{~min}\right)$ PCR amplification of the cDNA was carried out using the GeneAmp in situ PCR System 1000 (PE Biosystems). The direct fluorescent in situ PCR was performed as follows: slides were heated at $70^{\circ} \mathrm{C}$ before starting the reaction ("hot start"); the in situ PCR solution (preheated at $70^{\circ} \mathrm{C}$ ) was 10 $\mathrm{mM}$ Tris, $50 \mathrm{mM} \mathrm{KCl}, \mathrm{pH} 8.3$, dTTP, dCTP, dGTP, $200 \mu \mathrm{M}$ each, $200 \mu \mathrm{M}$ dATP and $5 \mu \mathrm{M}$ FITCdATP (Boehringer Mannheim), MRPI specific primers (forward 5'-CTGTTTTGTTTTCGGGTTCC-3'; reverse 5'-GATGGTGGACTGGATGAGGT-3'), $0.5 \mu \mathrm{M}$ each, and 10 units for reaction of IS-Amplitaq (PE Biosystems). The following thermal cycle was used: denaturation at $94^{\circ} \mathrm{C}$ for 1 min, annealing at $58^{\circ} \mathrm{C}$ for $30 \mathrm{sec}$ and extension at $72^{\circ} \mathrm{C}$ for $2 \mathrm{~min}$, repeated 15 times. After the amplification, the slides were washed twice with PBS for $5 \mathrm{~min}$ and then counterstained with Vectashield-DAPI (Vector Labs, Burlingame, CA) and directly analyzed under a fluorescent microscope (Leica Microsystem, Heerbrugg CH).
Controls were used for RT and IS-PCR, without RT and without primers. Primers were excluded from the PCR mix to establish whether non-specific elongation by Taq polymerase had occurred because of the nicks in the fixed cDNA. A noninfected liver biopsy from healthy subject was used as "no target control".

The morphology of HCV infected liver biopsies was maintained despite the multiple steps of fixation, permeabilization and RT, PCR (with thermal cycling).

Figure 1 shows the results of direct fluorescent RT-IS-PCR on HCV biopsies. We examined ten liver biopsies from patients with severe chronic hepatitis C, graded according to the severity of the necroinflammatory process (diffuse hepatocellular dammage). A strong positive signal for $M R P I$ was detected in all specimens (Figure 1a, 1b,1c), indicating a significant expression in the infected liver tissues. In contrast with the nearly absent expression reported in normal liver (Figure 1f), a consistent presence of MRP1 in HCV infected liver may support the hypothesis of an involvement of MRP1 in inflammatory conditions and in cellular dammage (Hipfner et al. 1999). Figure 1d shows the results obtained with the negative control, in which the RT reaction was omitted: no positive signal of MRPI expression was found and the level of background was very low.

A negative result was also obtained for the no primer control (Figure 1e). False positive signals, due to the Taq polymerase gap filling and nick repair activity on damaged nuclear DNA, were not detected because of the DNAase (RNA free) overnight pre-treatment previous to the RT and amplification steps.

We have described a new sensitive, specific and reproducible method to detect in situ MRPI expression that could be suitable for liver biopsies as well as for different tissue specimens. The possibility to detect varied expression of $M R P 1$ in liver pathologies other than cancer will add important clues on the role of the encoded protein and its regulation.

Fig. 1 - (Panel a, b, c) RT fluorescent in situ PCR on paraffin embedded liver biopsies from patients with severe HCV infection. A positive signal of amplification is clearly detectable, $M R P-1$ expression was visible after 15 cycles. Magnification 100 ( a), 400 (b), 1000 (c). (Panel d) No RT control. RT reaction has been omitted and no positive signal of MRPl expression has been found in liver biopsies. Magnification 200. (Panel e) No primer control. No false positive signals due to the Taq polymerase gap filling and nick repair activity were detected. Magnification 200. (Panel f) No target control. No signal of amplification has been found in a biopsy from the liver of a healthy control. Magnification 200. 

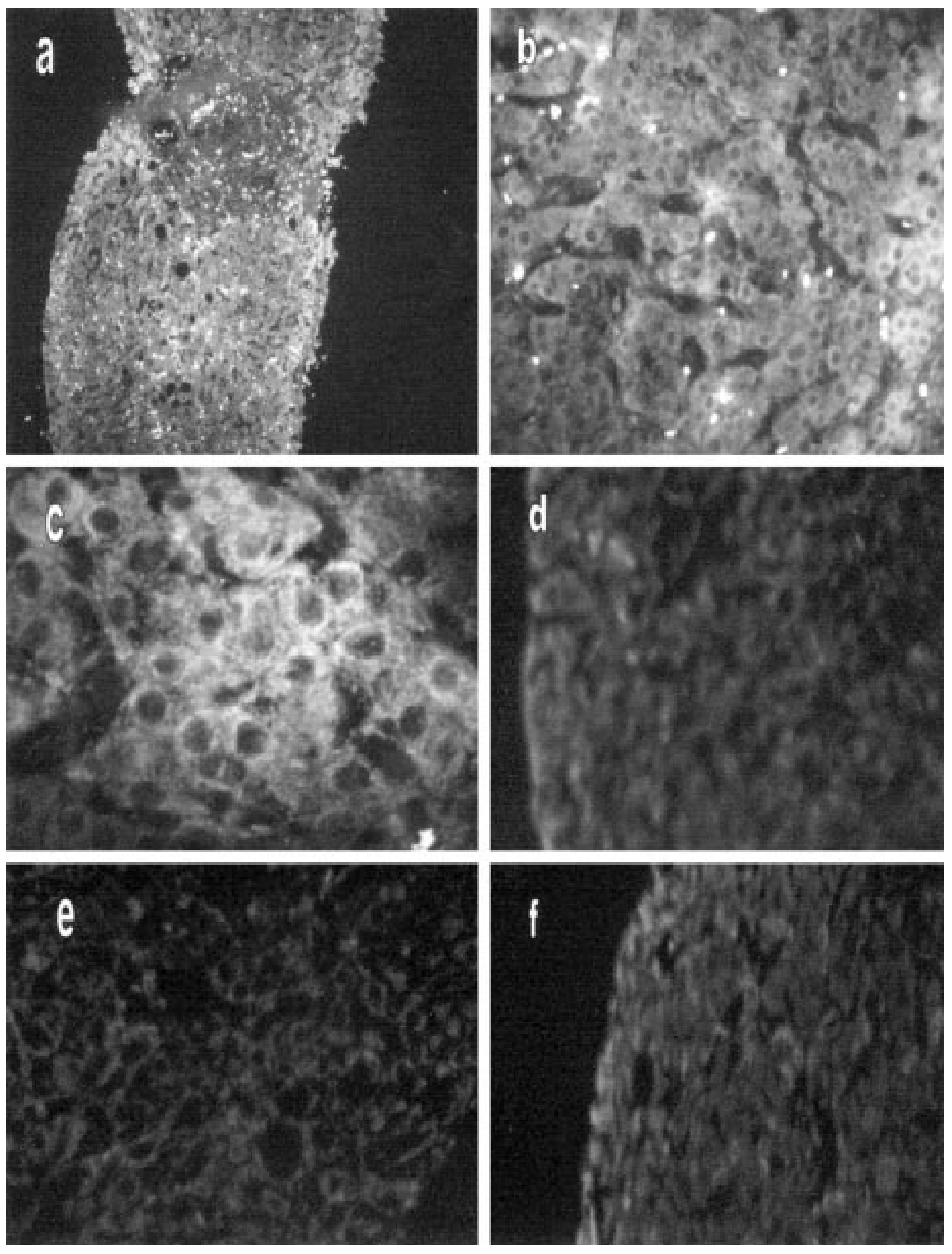


\section{ACKNOWLEDGEMENTS}

This study was partly supported by a $40 \%$ project of MURST and by IRCCS Burlo Garofolo "progetto ricerca corrente" n. 19/99 and "progetto finalizzato" ICS060.1/RF98.67. A. Spanò and E. Demori are recipients of fellowship from IRCCS Burlo Garofolo, Trieste.

\section{REFERENCES}

Dunn S.E., Hughes C.S., LeBlanc G.A., and Cullen J.M. Overexpression of a p-glycoprotein in hepatocellular carcinomas from woodchuck hepatitis virus-infected woodchucks (Marmota monax). Hepatology 23, 662-668, 1996.

Hipfner D.R., Deeley R.G., and Cole S.P.: Structural, mechanistic and clinical aspects of MRP1. Biochim. Biophys. Acta 1461, 359-376, 1999.

Hoofnagle J.H.: Management of hepatitis C: current and future perspectives. J. Hepatol. 31, Suppl 1, 264-268, 1999.

Kim Y.S., Cho S.W., Lee K.J., Hahm K.B., Wang H.J., Yim H., Jin Y.M and Park C.H.: Tc-99m MIBI SPECT is useful for noninvasively predicting the presence of MDR1 gene-encoded P-glycoprotein in patients with hepatocellular carcinoma. Clin. Nucl. Med., 24, 874-879, 1999.

Legrand O., Perrot J.Y., Tang R., Simonin G., Gurbuxani S., Zittoun R., and Marie J.P.: Expression of the multidrug resistance-associated protein (MRP) mRNA and protein in normal peripheral blood and bone marrow haemopoietic cells. Br. J. Haematol. 94, 23-33, 1996.

Matsunaga T., Shirasawa H., Hishiki T., Enomoto H., Kouchi K., Ohtsuka Y., Iwai J., Yoshida H., Tanabe M., Kobayashi S., Asano T., Etoh T., Nishi Y., and Ohnuma N: Expression of MRP and cMOAT in childhood neuroblastomas and malignant liver tumors and its relevance to clinical behaviour. Jpn. J. Cancer Res. 89, 1276-1283, 1998.

Minemura M., Tanimura H., and Tabor E: Overexpression of multidrug resistance genes MDR1 and cMOAT in human hepatocellular carcinoma and hepatoblastoma cell lines. Int. J. Oncol. 15, 559-563, 1999.

Takeuchi A., Kaneko S., Matsushita E., Urabe T., Shimoda A., and Kobayashi K.: Interferon-alpha modulates resistance to cisplatin in three human hepatoma cell lines. J. Gastroenterol. 34, 351-358, 1999. 